\title{
Hacer teología en medio de los pobres
}

\section{Víctor Codina, S. J.}

En una primera instancia, parecería que la teología, la ciencia sobre Dios, no está ligada a las condiciones espacio-temporales, sino que va más allá de lo geográfico e histórico. Parecería que la teología participa de la eternidad de su objeto y, así, sería válida para todos los tiempos y lugares, con tal que, como afirmaba Melchor Cano, parta de los lugares teológicos "mayores y fundamentales", que son la Escritura y la tradición. La teología escolástica en latín ha sido durante muchos años idéntica en todas las facultades teológicas, lo cual permitía trasladar profesores y alumnos de una facultad a otra sin dificultad. Esto parecía corroborar la unicidad y la universalidad de la teología, una teología romana, tuta, segura, válida e incluso obligatoria para todo el mundo.

Sin embargo, la sociología y la psicología del conocimiento nos advierten que las cosas no son tan simples y que aquellos lugares teológicos que Melchor Cano consideraba "secundarios", es decir, la razón natural, la filosofía y los acontecimientos históricos, son muy importantes. Hay que distinguir el "un solo Señor, una sola fe, un solo bautismo y un Dios y Padre de todos" (Ef 4,5-6) de la fe, de la teología, que siempre es una aproximación parcial, plural y limitada al misterio último. Y esto no es una novedad, la teología de Marcos es muy diferente de la de Juan, la teología latina es diversa de la oriental, y en el oriente, la reflexión alejandrina difiere de la antioquena, como en occidente, la de Tomás difiere de la de Buenaventura, como la del maestro Eckhart difiere de la de santa Teresa del Niño Jesús. Cada teología, según sujetos y tiempos, profundiza y refleja un aspecto del insondable misterio cristiano y todas ellas contribuyen al progreso del dogma, como afirmaba Newman. Por esto, cada teólogo debería señalar al comienzo de sus escritos cuándo y desde dónde hace teología, si desde Tübingen, París, Madrid, Roma, São Paulo, Bogotá, Boston, Nueva Delhi o Cochabamba... 
En el fondo, subyace aquí la teología de la Iglesia local $(L G, 23)^{\prime}$, que fue, según Karl Rahner, uno de los mayores aportes eclesiológicos del Vaticano II.

\section{Teología desde los pobres}

Esto supuesto, no puede extrañar que la teología latinoamericana, hecha en medio de los pobres, tenga que ser y sea diferente de la teología centroeuropea o noratlántica, la cual surge en un contexto de bienestar económico y democracia política, donde las necesidades humanas básicas están mayormente garantizadas. En consecuencia, su problemática se centra en temas como el sentido de la vida, la secularidad, el agnosticismo y el ateísmo. Esta teología centroeuropea entra en diálogo con la llamada primera ilustración, la modernidad, con la cual también dialoga el Vaticano II, en Gaudium et spes.

Tampoco debe extrañar que la teología latinoamericana, hecha desde un continente pobre y religioso, no solo difiera de la centroeuropea, sino que tampoco haya sido bien comprendida y muchas veces haya sido censurada como peligrosa y heterodoxa, desde otras teologías. Esto no es nuevo. El sermón profético del dominico Antonio de Montesinos, en La Española, en el adviento de 1511, no solo fue censurado por el gobernador Diego Colón, sino que también por el provincial de su propia orden dominicana Alonso de Loaysa ${ }^{2}$ y por Ginés de Sepúlveda, el teólogo laico oficial de Carlos V que se enfrentó con Bartolomé de Las Casas, en la disputa sobre las Indias ${ }^{3}$. En 1576, José de Acosta, en De procuranda indorum salute, afirma que los teólogos españoles juzgan a los teólogos misioneros de América sin conocer su contexto, como aquellos médicos, dice, que diagnostican y recetan medicinas desde lejos, sin conocer al enfermo ${ }^{4}$.

Hay que reconocer honradamente que durante casi 500 años, la teología dominante en América Latina fue, con algunas excepciones, fiel reflejo de la teología europea. En el Vaticano II, los obispos latinoamericanos constituyeron la llamada "mayoría silenciosa", pues no estaban al tanto de las nuevas corrientes teológicas centroeuropeas de mediados del siglo XX, ni se atrevían a expresar sus propias convicciones, quizás por miedo a ser tildados de comunistas. Pero en el llamado Pacto de las catacumbas de Santa Domitila, algunos obispos latinoamericanos, liderados por Hélder Câmara y Manuel Larraín, expresaron sus deseos pastorales de una Iglesia pobre y testimonial.

1. Es conocida la discusión entre J. Ratzinger y W. Kasper, en torno a la Iglesia local, con motivo del documento de la Congregación para la doctrina de la fe, Communionis notio, publicado en 1992.

2. B. de Las Casas, Historia de las Indias, Libro III, c. 4.

3. Cfr. G. Gutiérrez, En busca de los pobres de Jesucristo. El pensamiento de Bartolomé de Las Casas (Lima: Instituto Bartolomé de Las Casas, 1992).

4. J. de Acosta, De procuranda indorum salute, IV, c. 11, p. 92. 
El cambio nació en Medellín, en 1968, cuando los obispos latinoamericanos, convocados por Pablo VI para aplicar el Vaticano II a América Latina, realizaron una verdadera recepción creativa del concilio. Aunque asumieron la importancia de la eclesiología de la Iglesia local de la Lumen gentium, no partieron de ella, sino de la Gaudium et spes y de la teología de los signos de los tiempos, que constituye la originalidad mayor del Vaticano II y de lo que Juan XXIII deseaba del concilio. En realidad, la mayor novedad del Vaticano II consistió en afirmar que Dios actúa en la historia, que el Espíritu guía a la Iglesia y a la humanidad hacia el reino, que en los deseos y aspiraciones profundas de la humanidad Dios nos habla, y que a través del clamor del pueblo hay que discernir y escuchar la voz de Dios 5 .

Los documentos de Medellín no parten de las estructuras eclesiásticas, sino de la justicia y la pobreza, de la familia, de la educación y de la juventud; ven que el pueblo, como los israelitas en Egipto, está oprimido y clama libertad y justicia; reconocen que hay una situación de pecado estructural y que no se trata solo de la necesidad de promoción y progreso, sino de una verdadera liberación. Los documentos de Medellín utilizan una nueva metodología, inspirada en la Juventud Obrera Católica europea de Cardijn: ver, juzgar y actuar.

En Medellín, se pasa de la primera a la segunda ilustración, de la modernidad a la solidaridad, a la justicia y a los pobres, examinando las causas de la pobreza. En las décadas de 1970, 1980 y 1990, América Latina experimenta una verdadera irrupción del Espíritu, con el surgimiento de grandes obispos, verdaderos santos padres de la Iglesia de los pobres; con laicos, hombres y mujeres, cristianos, comprometidos con la Iglesia y la sociedad; con la aparición de una vida religiosa inserta en los pobres; con la fundación de las comunidades eclesiales de base; con la devolución de la Biblia al pueblo y con el testimonio de numerosos mártires, entre los cuales Mons. Romero es seguramente el más conocido.

En este contexto surge la teología latinoamericana de la liberación, que Gerhard Ludwig Müller, cuando todavía era prefecto de la Congregación para la doctrina de la fe, calificó como "una de las corrientes teológicas más significativas de la teología católica del siglo XX"

No es el momento de exponer aquí la génesis y la evolución de la teología de la liberación ${ }^{7}$. Baste recordar que existe una reflexión original sobre Dios como el Dios de la vida; sobre la Trinidad como comunidad amorosa, abierta al mundo;

5. P. Hünermann, El Vaticano II como software de la Iglesia actual (Santiago: Ediciones de la Universidad Alberto Hurtado, 2014).

6. G. Gutiérrez y G. L. Müller, Del lado de los pobres. Teología de la liberación, p. 29 (Madrid: San Pablo, 2013).

7. Cfr. M. Cheza, L. Martínez Saavedra y P. Sauvage, Diccionnaire de la Théologie de la Liberation (Namur, París: Lessius, 2017). 
sobre Jesús de Nazaret como liberador total y profeta del reino; sobre el Espíritu Santo, que actúa desde abajo, desde el de profundis de la historia; sobre María como mujer profética; sobre la Iglesia de los pobres y la eclesiogénesis, a partir de las comunidades eclesiales de base, y todo ello, desde la espiritualidad del seguimiento de Jesús, en la historia hacia el reino, y desde la opción por los pobres, en una teología atravesada por la misericordia: intellectus misericordiae (J. Sobrino).

Todos conocemos las dos instrucciones de la Congregación para la doctrina de la fe de 1984 y 1986, las cuales critican y amonestan a la teología de la liberación. Sin embargo, esta teología latinoamericana, más allá de las posibles ambigüedades en el uso del análisis social, de visiones excesivamente optimistas y utópicas sobre el futuro del continente, de formulaciones posiblemente imprecisas, del riesgo de cierta ética demasiado militante, voluntarista y poco sensible a la gratuidad del don del Espíritu..., se centra en algo profundamente bíblico e irrenunciable: el seguimiento del Jesús histórico hacia el reino y la consiguiente opción por los pobres.

Esta teología latinoamericana no brota de una inspiración puramente sociológica o política, sino de una experiencia evangélica, de la experiencia espiritual del encuentro del Señor en los pobres, en la línea de Mateo 25, de la experiencia nazarena del "cuando lo hicieron con algunos de los más pequeños de estos mis hermanos, me lo hicieron a mí" (Mt 25,40).

La opción por los pobres no se fundamenta en la bondad del pobre, sino en la ternura y la misericordia divina, que se compadecen ante el dolor y la aflicción del pueblo, cualquiera que sea su situación moral o personal (Puebla, 1142). Su fundamento no es sociológico o antropológico, sino estrictamente teológico. La afirmación de Benedicto XVI en Aparecida, donde declaró que la opción por los pobres está implícita en nuestra fe cristológica, es el mejor refrendo de la autenticidad cristiana del fundamento de esta nueva corriente teológica latinoamericana (Aparecida, 392). Y Aparecida saca las consecuencias: "todo lo que tenga que ver con Cristo tiene que ver con los pobres y todo lo relacionado con los pobres tiene que ver con Jesucristo" (Aparecida, 393). El papa Francisco reasume la temática de una Iglesia pobre y de los pobres y confirma la opción de Medellín (Evangelii gaudium, 186-216).

Si esto es así, podemos preguntarnos con sinceridad si todas las facultades de teología de América Latina y del Caribe, a partir de Medellín, han sido sensibles a la opción por los pobres, y si aceptamos la teología latinoamericana del seguimiento de Jesús de Nazaret, sea cual sea el nombre y el matiz que demos a nuestra teología. ¿Hemos intentado promover entre los estudiantes la sensibilidad hacia la justicia social, en la línea de Medellín? ¿Hemos animado a "bajar de la cruz a los crucificados de la historia" (Ellacuría)? ¿O seguimos reflejando, única o predominantemente, la teología clásica y moderna occidental, europea y 
norteamericana, tal vez pensando que la teología latinoamericana actual es más sociológica que teológica, una moda que con el tiempo se ha ido superando?

\section{Los pobres como lugar teológico}

Aún podemos dar un paso más. No se trata únicamente de optar por los pobres, opción que quizás nos sitúa en un plano de superioridad respecto a ellos, sino de considerar a los pobres como sujetos humanos, culturales, religiosos y teológicos. No basta con elaborar un análisis sociológico, sino que, además, hay que hacer un análisis antropológico, cultural y religioso de la realidad. Es el paso de una Iglesia para los pobres a una Iglesia pobre y de los pobres, en la cual los pobres son sujetos prioritarios.

En la Iglesia, en concreto, en la teología, no nos hemos tomado demasiado en serio la exultación mesiánica de Jesús, quien lleno de Espíritu bendice al Padre, porque ha ocultado los misterios del reino a los sabios y prudentes de este mundo y se los ha revelado a la gente sencilla, a los pobres, a los nepioi, a los pequeños, a los insignificantes (G. Gutiérrez), a los "nadies" (E. Galeano) (Lc 10,21; Mt 11,25) .

Frente a la actitud de los escribas y fariseos, llena de orgullo y autosuficiencia, Jesús alaba la actitud del pueblo sencillo y pobre, el óchlos, que lo sigue con fidelidad y confianza. Estamos en el corazón del evangelio, en las bienaventuranzas a los pobres tanto materiales como espirituales (Mt 5,1-12; Lc 6), estamos ante la actitud de todo creyente que se ha de situar ante el Padre como los niños y los pequeños, con plena confianza (Mt 18,1-5).

El evangelio del nacimiento de Jesús en Belén no se anuncia a los grandes del mundo, sino a unos pastores pobres y marginados (Lc 2,8-20). Dos ancianos pobres desconocidos, Simeón y Ana, son quienes descubren en aquella pareja de campesinos que llevan el niño al Templo, al mesías prometido y a la gloria de Dios (Lc 2,22-38), mientras los sacerdotes, los escribas y los fariseos permanecen ciegos e insensibles ante el misterio.

Existe una especial connaturalidad entre los pobres y los misterios del reino, porque ellos comprenden mejor que nadie que esta dura e injusta realidad no puede ser la definitiva, que ha de haber algo más y que ha de haber Alguien más, que un día ha de prevalecer la justicia y la bondad sobre la injusticia y la corrupción. Como afirma Aloysius Pieris, Dios y los pobres han establecido

8. Cfr. P. Trigo, Cristología latinoamericana (Puebla: Universidad Iberoamericana de Puebla, 2010), donde hace un análisis exegético de la exultación mesiánica de Jesús y su relación con el resto del evangelio. Cfr. también V. Codina, "La fe de los insignificantes", Revista Latinoamericana de Teología 76 (2009), 89-97. 
una alianza para la realización del reino de Dios, una batalla contra el enemigo común, Mammón, el ídolo de la riqueza?

Lo que afirma el Vaticano II sobre el sensus fidelium $(L G, 12)$ y la unción del Espíritu (1 Jn 2,20.27) se aplica a los pobres e insignificantes de forma especial. La célebre distinción entre la fides quae, o la dimensión doctrinal de la fe, y la fides qua, o dimensión existencial de la fe, halla, en el caso de los pobres, un claro ejemplo: aunque su fides quae sea muchas veces débil, su fides qua, su vivencia de la fe, es fuerte y profunda.

De aquí la importancia que el magisterio latinoamericano ha dado a la fe del pueblo sencillo, a la religiosidad popular, a su lectura de la Palabra y a las comunidades eclesiales de base. Aparecida habla de la sed de Dios, que solo los pobres y sencillos reconocen (Aparecida, 258, 549), de su fe en un Dios cercano a los pobres, de su fe en un Dios del perdón y de la reconciliación, de su fe en el Cristo sufriente, de su profunda devoción a María, de su fe en la lucha por la justicia, de su esperanza contra toda esperanza, y de la alegría de vivir, aun en condiciones difíciles (Aparecida, 7). Esta fe se expresa en muchas formas de devoción, en peregrinaciones a santuarios, en procesiones, en el culto a los santos, en danzas, en fiestas, en vía crucis, en promesas, en oraciones en familia (Aparecida, 262), y en una síntesis entre fe cristiana y cultura (Aparecida, 264).

Esto no es una invitación a la pasividad y al conformismo pastoral, pues Aparecida también afirma que una fe reducida a prácticas de devoción fragmentadas, a la participación ocasional de los sacramentos, a la repetición de principíos dogmáticos y morales, poco a poco se erosiona y a la larga sucumbirá al embate del tiempo (Aparecida, 12). De aquí que se invite a pasar de una pastoral conservadora a otra misionera, a una Iglesia en salida, a procurar una mejor formación cristiana al pueblo sencillo (Aparecida, 370).

Estamos, pues, ante un nuevo lugar teológico, que se añade a los lugares teológicos clásicos de Melchor Cano. Quizás esto nos parecerá menos extraño si recordamos un texto muy conocido de Tomás de Aquino, en el cual reconoce la existencia de dos cátedras en la Iglesia: la cathedra pastoralis de los que ejercen el ministerio ordenado jerárquico, singularmente los obispos, y la cathedra magistralis de los teólogos ${ }^{10}$. Ambos magisterios no son paralelos, sino convergentes, a veces se identifican, como en muchos padres de la Iglesia; a veces, hay tensiones entre ambos. Según Newman, las tensiones bien llevadas conducen a un equilibro mutuo" ${ }^{11}$.

9. A. Pieris, El reino de Dios para los pobres. Retorno a la fórmula de Jesús, p. 52 (Bilbao: Mensajero, 2006).

10. Quodlibet III, 9, ad 3; In IV Sent, d 19,2,2, 1 qa 2, ad 2.

11. Cfr. J. M. R. Tillard, Église d'Églises. L'ecclésiologie de communion, pp. 152-154 (París: Cerf, 1987). 
Pues bien, la cathedra magistralis no solo corresponde a los teólogos que ejercen la docencia universitaria, sino también a grupos de teólogos más amplios y carismáticos, como las doctoras de la Iglesia Catalina, Teresa de Jesús y Teresa del Niño Jesús, Edith Stein..., y a figuras del magisterio espiritual, como Francisco de Asís, Ignacio, Juan de la Cruz, Carlos de Foucauld.

Más aún, creemos que también se debe incluir aquí, en esta cátedra magisterial de la que habla santo Tomás, al magisterio teológico de los pobres. El papa Francisco se refiere a este tema en Evangelii gaudium, posiblemente influido por la corriente teológica liberadora argentina ${ }^{12}$. No solo habla del lugar privilegiado que los pobres ocupan en el pueblo de Dios ( $E G, 197-201)$, sino que también señala la fuerza evangelizadora de la religiosidad popular $(E G, 122-126)$ : el pueblo se evangeliza a sí mismo (Puebla, 450). La religiosidad popular es espiritualidad y mística popular, espiritualidad encarnada en la cultura de los sencillos, donde se acentúa más el credere in Deum que el credere Deum. De modo que la religiosidad popular es un lugar teológico al cual debemos prestar atención, sobre todo, de cara a la nueva evangelización $(E G, 126)$.

Indudablemente, estas nuevas afirmaciones de los pobres y de su piedad como lugar teológico y cátedra magisterial plantean muchas preguntas, cuyas consecuencias son de largo alcance. En primer lugar, esta religiosidad popular, en el fondo, es una crítica profética a una Iglesia clerical y elitista, muy dogmática y moralista, de la cual la mayor parte de gente sencilla y pobre se siente marginada y excluida. ¿Quién del pueblo comprende las profesiones de fe dogmáticas, los documentos del magisterio conciliar, pontificio o episcopal, las oraciones litúrgicas de la eucaristía, gran parte de las homilías, la legislación canónica, los moralismos y la casuística?

Por eso, el pueblo se agarra a los sacramentales - el agua bendita, las palmas, la ceniza, las bendiciones, las velas, las imágenes, las procesiones...-, a la devoción a los santuarios de María y del Señor, etc. El pueblo tiene un sentido mucho más vivo de lo simbólico y lo encarnatorio de la fe, de lo que Rahner llamaba die Sinnlichkeit der Gnade, la sensibilidad y la encarnación de la gracia, que los intelectuales.

Pero la fe del pueblo no es solo una crítica a cierto tipo de teología y de pastoral, sino que también es un clamor y un grito profético, que pide otro estilo de Iglesia y de teología, más familiar y cercana, más nazarena, más popular, más semejante a la de Jesús de Nazaret y a sus comparaciones y parábolas, que el pueblo fácilmente comprende y asimila.

12. Cfr. J. C. Scannone, La teología del pueblo. Raíces teológicas del papa Francisco (Santander: Sal Terrae, 2017); F. Luciani, El papa Francisco y la teología del pueblo (Madrid: PPC, 2016). 
¿Aceptamos el magisterio popular de los pobres y nos enriquecemos con todo lo que su fe y su religiosidad nos pueden aportar? El divorcio entre la fe y la vida de muchos cristianos, ¿no se deberá a que no partimos de sus problemas y dificultades, sino a que desde arriba lanzamos rocas teológicas, para ellos incomprensibles? ¿No será nuestra teología muy clerical y poco laical, machista y poco atenta al genio femenino, muy occidental y poco ligada a las culturas originarias, muy alejada de los problemas cotidianos del pueblo pobre?

Seguramente, muchos de los estudiantes de teología de las facultades latinoamericanas proceden de ambientes populares. ¿Partimos de su piedad popular y de sus vivencias sencillas, o las desconocemos y edificamos castillos de naipes teológicos, que luego se les caerán y no les servirán para comunicarse con su pueblo?

\section{Conclusión narrativa}

Al finalizar un curso de formación cristiana para adultos, en un barrio popular de la periferia de Cochabamba, una mujer exclamó: "Diosito nos acompaña siempre". Esta exclamación constituye una verdadera profesión de fe del pueblo pobre.

En Bolivia, como en otros países de América Latina, el pueblo es muy aficionado a los diminutivos: pancito, cafecito, maestrito, padrecito, madrecita, soldadito, angelito, muertito, ahorita... Estos diminutivos significan familiaridad, cercanía, cariño, algo entrañable y sencillo. En este contexto se puede comprender que también Dios sea llamado "Diosito".

Llamar "Diosito" a Dios está muy lejos de concebirlo como el Primer motor inmóvil, la Causa de las causas, el Ser necesario y absoluto, el Ens a se, el Ser del cual no se puede pensar nada mayor, tal como lo formularon los filósofos helénicos o escolásticos medievales. No es tampoco el Dios tremendo y fascinante, el "totalmente Otro" de los fenomenólogos de la religión.

"Diosito" no es el misterio absoluto y sin orillas, das Geheimnis, el Dios siempre mayor, el Dios inaccesible, envuelto siempre en la tiniebla de lo incognoscible infinito. Tampoco es el Dios "omnipotente y sempiterno", al que invoca de ordinario nuestra liturgia, en sus oraciones. Menos aún, "Diosito" no es el Yahvé terrible, que se manifiesta entre rayos y truenos, en el Sinaí; ni es el juez castigador implacable de muchas predicaciones moralizantes. Tampoco es el Dios del credo niceno-constantinopolitano.

"Diosito" es un Dios cercano, familiar, bueno, perdonador, misericordioso, que desea que seamos felices, que tengamos vida en abundancia. Es el mismo Dios al que Jesús llamaba Abbá, es decir, "papito", incluso en Getsemaní, en los momentos de angustia ante la cercanía de su pasión (Mc 14,36). "Diosito" refleja una imagen paterna y también materna de un Dios que no se olvida de nosotros, que tiene entrañas de misericordia, que nos cuida y nos protege (Is 49,5 ). 
Pero este Diosito, añadía la sencilla mujer cochabambina, "nos acompaña siempre". No es un Dios que permanece invulnerable e insensible en la lejanía, como los dioses del Olimpo, ni nos deja abandonados a nuestra propia suerte, como náufragos en medio del mar de la vida, sino que, como Yahvé, camina con su pueblo, escucha el clamor de los oprimidos en Egipto, acompaña a los israelitas en su marcha por el desierto, en su historia de luces y sombras, y les hace retornar del exilio de Babilonia a Palestina.

Es el Señor resucitado que se unió como peregrino desconocido a los discípulos de Emaús y primero les preguntó de qué iban discutiendo por el camino, y solo después les explicó las Escrituras y compartió con ellos el pan (Lc 24,13-35). Es el Señor que dijo que estaría siempre con nosotros hasta el fin de la historia (Mt 28,20) y que, a través del Espíritu, acompaña a la Iglesia en su peregrinación, guía a la humanidad y llena el universo.

"Diosito" nos acompaña siempre a lo largo de nuestra vida, en momentos de felicidad y de turbación, y no nos abandonará en el momento de nuestra muerte, porque es el que resucitó a Jesús de entre los muertos y también el que resucitará nuestros pobres cuerpos mortales ( $\mathrm{Rm} \mathrm{8,11;} \mathrm{Flp} \mathrm{3,21).} \mathrm{"Diosito"}$ fundamenta nuestra esperanza, porque nos acompaña siempre, es el Dios-connosotros, el Emanuel.

Muchos teólogos han buscado una fórmula breve del cristianismo, que compendie el credo y responda a nuestros días. "Diosito nos acompaña siempre" puede ser una fórmula breve, que resume toda la revelación bíblica, expresada a través del sentido de la fe del pueblo sencillo latinoamericano. "Diosito nos acompaña siempre" resume, en lenguaje popular, gran parte de la historia de la salvación bíblica. Es una versión popular del evangelio, es como el credo de los pobres.

La expresión "Diosito nos acompaña siempre" es un grito profético ante los sectores del primer mundo, y también de algunos latinoamericanos, para quienes Dios ha muerto y es algo absurdo, que pertenece a la época preindustrial y precientífica, un residuo cultural ante el cual vale más ser escépticos e indiferentes, permanecer en un prudente gnosticismo y guardar silencio. Frente a estos sectores ilustrados, el pueblo pobre y sencillo confiesa que Dios realmente existe y nos acompaña siempre. No es un enigma, no es un absurdo, es un misterio de cercanía y de bondad, es "Diosito".

Hacer teología en medio de los pobres supone no solo optar por ellos y ser solidarios con ellos, sino que también implica aceptar que muchas veces los pobres nos evangelizan y son nuestros maestros. La afirmación del obispo poeta Pedro Casaldáliga sobre Monseñor Romero, "Los pobres te enseñaron a leer el evangelio", se puede extender a todos nosotros. 